I Universidade Federal Fluminense (UFF), Departamento de

Antropologia, Niterói, RJ, Brasil

renatagoncalves@id.uff.br

https://orcid.org/0000-0002-5096-0259

Renata de Sá Gonçalves '

\title{
A CIÊNCIA E A POLÍTICA COMO VOCAÇÃO - O DISCURSO DE MERKEL E A PRIMEIRA ONDA DA PANDEMIA DE COVID-19 NA ALEMANHA ${ }^{1}$
}

Este artigo pretende indicar apontamentos sobre a ciência e a política, tais como formuladas pelo sociólogo Max Weber, a partir da análise da condução e das primeiras medidas para a gestão da crise diante da pandemia da covid-ı 9 em 2020, quando eclodiu a chamada primeira onda de infecções. Para tanto, o artigo se propõe a trazer um relato pessoal da experiência da pesquisadora brasileira na Alemanha no referido ano, em contraste com a dimensão no Brasil.

Em dezembro de 20I9, eu e minha família nos mudamos para a cidade universitária de Tübingen, no sudoeste da Alemanha. Nesse lugar, e como estrangeira, estranhei muitas rotinas, modos de se relacionar e de estar no mundo. Uma nova vida em um lugar diferente pela língua, pelos hábitos e pelas sociabilidades nos ambientes que passei a frequentar.

A pequena cidade difere em escala da grande metrópole do Rio de Janeiro, de onde venho. Em Tübingen residem cerca de 90 mil habitantes, e a maior parte deles se vincula à vida da universidade. Desde nossa chegada, com o registro obrigatório no departamento para estrangeiros no escritório da municipalidade e entrada na universidade, fomos acolhidos com orientações sobre serviços públicos, apoio educacional e dicas diversas sobre a vida na cidade. Meus filhos de cinco e dez anos ingressaram na creche e na escola pública perto de casa, a cinco minutos a pé.

Em março de 2020, tudo mudou por ali com a ameaça da doença causada pelo vírus SARS-Cov-2 ou novo coronavírus. A doença provocada pelo vírus 
e identificada inicialmente na China se alastrava entre países de diversos continentes, e as suas consequências ainda pouco se conheciam. Em I I de março de 2020, a Organização Mundial de Saúde (OMS) classificou o estado da contaminação da doença causada pelo novo coronavírus como "pandemia" de covid-I9. A mudança de classificação se deveu à disseminação geográfica rápida que apresentou níveis alarmantes de contaminação e a uma preocupação em atentar para a necessária ação imediata dos governos.

Naquele momento, eu e minha família passamos a viver as restrições sociais diárias de acordo com o isolamento social instaurado, com a suspensão de atividades presenciais nas escolas e na universidade. Apenas o comércio essencial, supermercados e farmácias, permaneceu em funcionamento. Assim se passou em outros países da Europa.

Naquele início de março de 2020, a Alemanha figurava entre os países mais afetados pela pandemia, com I 2 mortes e mais de 8.000 casos confirmados. Com a identificação de um importante número de pessoas contaminadas e as necessárias medidas de controle, a chanceler Angela Merkel fez um pronunciamento ${ }^{2}$ transmitido pela televisão em I 8 de março de 2020 , apelando para que a população levasse com muita seriedade a pandemia que estava em curso exponencial. Em suas palavras, a Alemanha enfrentaria os maiores desafios, comparáveis aos da Segunda Guerra Mundial, e a sociedade alemã deveria estar preparada para uma "ação solidária coletiva".

Em tom sério e objetivo, Merkel destacou a gravidade e a extensão da crise sanitária mundial. Em suas palavras embasadas por pesquisas e projeções, e acompanhada pela declaração da OMS, Merkel explicava que o contágio poderia atingir até 70\% da população e que medidas severas eram necessárias para que houvesse um progressivo e cauteloso programa de mitigação e de controle do vírus, mas também confiava na cooperação social mais ampla devido ao desafio econômico que se avizinhava.

Em contraste com a posição de outros chefes de Estado, Merkel desde cedo, diferenciou-se por não desprezar a escala do problema epidemiológico, político, econômico e social que se erguia. Para reduzir a velocidade de propagação do vírus, medidas foram tomadas como o fechamento de escolas, de vários estabelecimentos de comércio e de espaços públicos, sem contudo impor a quarentena compulsória a seus cidadãos.

O referido discurso ganharia destaque na mídia local e, também mundialmente, sendo citado com frequência desde então em reportagens e ganhando reconhecimento público, a exemplo do prêmio Discurso do Ano concedido pelo Departamento de Retórica Geral da Universidade de Tübingen.

Em comunicado no final de $2020^{3}$ feito pela Universidade de Tübingen, o júri do prêmio elegia o discurso da chanceler como o melhor daquele ano. Os especialistas em retórica destacaram que, no discurso televisivo, "Merkel demonstrou de maneira impressionante [...] como a razão, auxiliada pela retórica, pode 
levar à ação, e como a boa retórica pode fomentar o sentimento de coesão na comunidade". Na avaliação, os especialistas que formaram o júri afirmavam que o discurso histórico foi de importância central para o gerenciamento bem-sucedido da primeira onda da pandemia. "Esse discurso televisionado provavelmente influenciou diretamente a população alemã de uma forma que quase nenhum outro discurso dos últimos anos fez". Os parâmetros de avaliação, englobavam eficácia, desempenho argumentativo e qualidade estilística da fala e avaliava todo o encadeamento lógico do locutor.

Como fio condutor, o discurso destacou a exigência de responsabilidade social. Merkel deixava claro que os regulamentos por si só não eram suficientes para conter a pandemia: "Todas as medidas governamentais seriam ineficazes se não utilizássemos os meios mais eficazes para evitar que o vírus se propagasse muito rapidamente: E somos nós mesmos".

Como destacado pelo júri, Merkel se dirigiu repetidamente a grupos específicos da população de forma direta, criando proximidade, usando um amplo repertório de dispositivos retóricos estilísticos para enfatizar a gravidade da situação. Ela convincentemente trouxe sua própria experiência, usou sua própria biografia e autoridade para defender sua causa como oradora.

O discurso de Merkel também foi comparado às reações e aos discursos de outros chefes de governo europeus. Enquanto o francês Emmanuel Macron tendeu a fazer declarações autoritárias e metáforas de guerra radicais em seu primeiro discurso televisionado, e o inglês Boris Johnson tendeu a minimizar os perigos, a chanceler Merkel usou linguagem informativa, objetiva e argumentação cientificamente embasada. Ao fazê-lo, segundo o júri, gerou de forma exemplar o equilíbrio entre razão e empatia, conquistando grande reconhecimento internacional. Obteve assim um forte impacto emocional ao tornar claras as consequências da pandemia: "Não são apenas números abstratos nas estatísticas, mas um pai ou um avô, mãe ou avó, companheira, são gente. E somos uma comunidade em que cada vida e cada pessoa conta".

Dois meses depois do pronunciamento de Merkel, já em I 8 de maio, os números divulgados na Alemanha totalizavam I77.289 casos confirmados e 7.000 mortes, demonstrando a rapidez e agressividade do contágio, nessa chamada primeira onda da pandemia. O número de mortes, entretanto, permanecia proporcionalmente inferior ao dos países vizinhos europeus, sobretudo a Itália, a Espanha e a França, cujas taxas de letalidade se mostraram bem mais elevadas. Com as mortes numerosas na Itália, e o cenário mais positivo na Alemanha, a imprensa mundial passou a destacar este último como o país que melhor gestava a crise, ou um dos melhores lugares para se viver em um contexto mundial, já tomado pela pandemia. 
Alguns aspectos foram levantados para os relativos bons resultados na Alemanha naquela ocasião. Um deles foi a capacidade de realização de testes em grande escala desde os primeiros casos em fevereiro, o que permitiu rastrear e prevenir novos contágios. Outro aspecto teria sido o bem estruturado sistema de ciência, o desenvolvimento de pesquisa nas distintas áreas, e a expertise e desenvolvimento tecnológico em saúde e medicina. E, ainda, a garantia de direitos básicos assegurados por uma política de bem-estar social mais ampla.

Se condições preexistentes ajudavam, houve ainda forte reforço em investimentos e melhorias de condições de saúde e de planos para assegurar a economia e a manutenção de empregos. Um plano imediato para ampliar a capacidade do sistema de saúde foi colocado em prática, mesmo diante do já bem estruturado sistema de saúde alemão, um dos mais fortes da Europa, com maior número de leitos e unidades de terapia intensiva em relação proporcional à população do país.

O novo desafio foi lidar com o controle da circulação mundial do novo coronavírus, e com sua potencial agressividade no contato com toda a população não imune. Como indicado pelos especialistas e pelo Instituto Robert Koch (RKI, agência responsável pela prevenção e controle de doenças na Alemanha), em acordo com os dados baseados na experiência dos outros países, a diminuição do contato social foi entendida como a medida mais eficiente para se evitar uma disseminação em massa e descontrolada do vírus. Caso contrário, não haveria chance para uma preparação mais adequada do sistema de saúde, com a demanda aumentada de atendimentos nos hospitais e a necessidade de mais profissionais.

Merkel destacou os epidemiologistas, os estatísticos, entre outros tantos cientistas dedicados aos estudos em permanente curso que orientam o modo de condução das decisões políticas por meio da transparência dos dados, da projeção dos riscos de saúde, econômicos, políticos, sociais e das possíveis alternativas. Com experiência e formação em pesquisa, e título de doutorado em química quântica, Merkel soube fazer um bom balanço entre o avanço e a cautela. A potencialidade da investigação científica em testar, comprovar, somava-se ao esforço necessário em não pular etapas e em cumprir o passo a passo para se chegar a resultados seguros. Cada passo pensado, debatido, e avaliado permitiu uma adequada análise dos limites que se impunham como necessários.

Como indica Speck (2020), os cientistas não tiveram somente forte presença na mídia, com podcasts diários que gozaram de ampla aceitação popular, mas também pautaram as decisões sobre a adaptação das medidas políticas para combater a pandemia. Outra influência de Angela Merkel foi a de imprimir um viés suprapartidário ao combate à pandemia. Como sugere Speck (2020: 242), ela conseguiu, junto com os governos locais, liderados por diferentes par- 
tidos, conter a politização do tema. A política de combate ao vírus se tornou uma política de Estado, não de determinado partido político.

O mérito pessoal aferido a uma liderança que já está há I5 anos no governo é inquestionável. Mas também há um modo de situar a crise, que tem raízes sociais mais profundas. E aqui podemos nos aproximar de algumas ideias do sociólogo alemão Max Weber, especialmente, em dois de seus escritos "A ciência como vocação" e "A política como vocação", publicados em I9I9. ${ }^{4}$

Como destaca a socióloga Glaucia Villas Bôas (2008), as conferências seriam textos sobre questões da cultura moderna: a ciência e a política, a construção da nação alemã e de um estado nacional moderno, dependente da prontidão dos indivíduos de se engajar em tarefas que exigem autorrenúncia e distanciamento. Algumas ideias abrangentes de Weber nesses dois ensaios nos inspiram a compreender a racionalidade da ciência e da política referidas a uma equação dinâmica entre meios e fins.

Como afirmava Weber (I972a) na conferência "A ciência como vocação", a própria prática científica contribui para a racionalidade humana, especialmente por promover o desenvolvimento de métodos de pensamento. A pesquisa pressupõe inspiração, mas também trabalho, método e rigor, e a consciência de que as verdades e descobertas não são permanentes, mas estão sempre em processo crítico de questionamento. A escolha que faz um cientista diante de um conjunto de decisões é assim ascética, autolimitada, assentada na ética da responsabilidade.

A racionalidade da ciência ocupou lugar central no tratamento dado na gestão da crise sanitária por parte de Merkel, cuja presença de dados e de pesquisas científicas foi levada a sério. Ao mesmo tempo, um tipo de racionalidade política a acompanhou.

Em "A política como vocação", Weber (I972b) indicava como a racionalidade do sistema político depende de organizações políticas que balizam o poder individual e exercem o monopólio do poder de uma sociedade. Viver para a política ou viver da política são distinções necessárias à racionalidade do sistema político, cujo sucesso depende da ação especializada no desempenho e no conhecimento das organizações que limitam a atuação da política. O político que vive para a política, e não da política, representaria o tipo ideal no âmbito de atributos do político vocacionado com dedicação apaixonada a uma causa, movido pela clareza e pela conduta responsável em torno de ideais e utopias, e com senso de responsabilidade como guia de ação e de proporções.

O modelo alemão contemporâneo chama a atenção pela característica descentralizada da sua política: pouco poder para a federação, mais responsabilidades para as cidades e os estados federados. Há uma delimitação sobre o que é a função do governo central, dos estados e das cidades e uma dinâmica colaboração, com certas autonomias (certamente nem sempre bem equacionadas) entre cidades e estados. Além disso, a atuação e o reconhecimento da 
sociedade civil não são menos relevantes. A confiança em uma relativa cooperação da população, destacada no referido pronunciamento de Merkel, se ancora na atuação das mais diversas organizações e associações locais, em bairros, em escolas, em municipalidades. As organizações estão não apenas nas capitais, mas também em pequenas cidades e em zonas rurais.

E aqui chegamos a um ponto importante: a capilaridade das tomadas de decisões que, horizontalizadas, podem ressoar diversamente, tanto positivamente, como de forma reativa. Senti pessoalmente esse forte aspecto de decisões compartilhadas no meu dia a dia. No mural do prédio onde eu residia, um morador afixou um bilhete com a oferta de ajuda para compras e o contato telefônico para realizar essa tarefa para os vizinhos que desejassem. Na caixa de correspondência, panfletos da associação do bairro com telefones de apoio psicológico. Campanhas dos lares de idosos sugeriam que as crianças fizessem cartões para alegrar os avós. Os serviços de atendimento médico por telefone e a possibilidade de realizar consultas a distância para receber orientações e realizar testes rápidos em estações de atendimento ao público a que se pode ir com facilidade foram divulgados amplamente.

No início do mês de maio de 2020, mediante estudos e índices que comprovariam um determinado controle da contaminação pelo vírus, a chanceler se reuniu com os representantes dos estados para implementar o início do relaxamento de algumas medidas. Um novo plano passou a ser organizado em cada estado, e localmente em cada cidade. A interpretação dos dados em cada estado e cidade balizava o quanto se poderia ou não relaxar algumas restrições, como e quando fazê-lo. Medidas de distância entre pessoas e do uso obrigatório de máscaras em lojas e transporte público foram adotadas.

Alguns segmentos da escola de educação básica começaram a retornar com atividades presenciais, horários reduzidos e número limitado de pessoas, mediante o cumprimento de medidas específicas de higiene. A universidade passou a enviar mensagens mais frequentes com orientações diversas sobre novas organizações e fóruns de discussões para as atividades que seriam realizadas a distância, com o permanente monitoramento das possibilidades futuras dentro dos limites a ser adotados.

Sentimentos contrastantes conviviam numa arena disputada. O sentimento de segurança e o de reconforto se mostraram presentes na experiência local, de cada um, no seu cotidiano de relações. Um ponto muito caro a uma população que rejeita a limitação de liberdades conquistadas e rememoradas ao longo de sua história e tem na garantia da liberdade um valor central a ser constantemente protegido e reforçado nas atitudes de adesão e respeito às necessidades de cada um e de todos e do fortalecimento de ações solidárias para mitigar as perdas de renda e de oportunidades de trabalho.

Em paralelo, uma indisposição quanto às medidas restritivas deu também lugar a reações de rejeição ao controle social, à resistência à centralização 
de decisões. Houve a presença de manifestantes reagindo contra as restrições, o confinamento, as vacinas, por meio de passeatas contra o que alegavam ser limites à liberdade de expressão individual. A oposição a tais medidas se tornou mais difundida entre a população desde o primeiro confinamento coletivo, em março e abril daquele ano. Para muitos, o medo inicial de se contaminar com o vírus, deu lugar a temores quanto às consequências econômicas de uma paralisação prolongada.

Houve ainda reação, como descrito por Speck (2020), que levou ao extremismo de direita, como a do partido AfD, cujos representantes tentaram capitalizar politicamente em cima das medidas de restrição de circulação e da desaceleração abrupta das atividades econômicas. Alguns participaram de protestos organizados por negacionistas. A tônica era 'antiEstado', em defesa da liberdade individual. Mas como alerta Speck, o resultado dessas investidas do AfD era pífio, talvez porque o ideário das liberdades individuais não ressoou com os ativistas do AfD. Como esclarece o autor, em outros tempos, o partido apregoou exatamente o contrário: a subordinação do indivíduo e da igualdade cidadã aos interesses do "povo alemão".

Em meio a toda essa conquista como descreveu Merkel naquela primeira fase da crise epidemiológica: "caminhamos sobre uma fina camada de gelo", o que demonstrava não ser possível dar a guerra por vencida, quando ela ainda estava em pleno curso e longe de seu fim.

O conforto e a objetividade no tratamento da primeira onda, os bons resultados na redução do número de infectados e um relativo controle da situação, com medidas de testagem em massa e rastreamento de casos, garantiram um verão com relaxamento de restrições, viabilizando mais encontros, abertura de comércio, bares, restaurantes, piscinas públicas, viagens de turismo, retorno a muitas atividades em espaços e clubes recreativos e a volta às atividades nas escolas.

Uma aparente conquista que marcou o fim do primeiro semestre de 2020 na Alemanha e seu bom desempenho na gestão de uma crise que parecia mais controlada, tomaria outra feição nos meses de setembro de 2020, após o verão, quando as infecções voltariam a subir. A população e os governos locais já demonstravam mais desacordos e visíveis tensões impactavam o objetivo comum de medidas restritivas coordenadas. A descentralização dos estados também indicava medidas distintas e problemas na abordagem e decisões ao longo de uma pandemia que se já se estendia para além do imaginado. A fina camada de gelo parecia se romper. E novas ondas se aproximavam.

A chamada segunda onda se avolumava após o verão europeu. A falsa sensação de segurança teria permitido que os governos locais, mesmo sob apelo de Merkel, tivessem sido condescendentes no afrouxamento precoce das medidas de controle. No final de outubro, um acordo com o governo federal definiu o fechamento dos bares e restaurantes por um mês. Os contatos seriam 
limitados a duas unidades familiares. As escolas e o comércio ficariam fechados, com a expectativa de reabertura no Natal.

Em meados de dezembro de 2020, nove meses após decretada a pandemia pela OMS, a Alemanha somava cerca de 23.000 mortos entre seus 83 milhões de habitantes. O aumento exponencial dos contágios causava preocupação e forçou a mais uma paralisação das atividades, restringindo e regrando até as festas familiares de fim de ano. Em dezembro de 2020, a incidência no país era maior que na França e Espanha, e próxima à do Reino Unido, conforme os dados do Centro Europeu para o Controle de Enfermidades.

Merkel nessa situação, novamente, com um discurso emocionado, divulgado no início de dezembro, informava que o governo federal estava promovendo responsabilidade e união, e lutaria com grande comprometimento pessoal para garantir que os residentes na Alemanha "como sociedade", enfrentassem consistentemente a ameaça representada pela pandemia.

Diante desta trágica pandemia, poderíamos pensar que estamos todos no mesmo barco. Mas, não. As realidades do norte ou do sul do globo são muito distintas, resultadas de processos sócio-históricos próprios. Na Alemanha, a execução de ações descentralizadas vêm em seu favor engendrando a capilaridade de modos de organização e de tomada de decisões. O poder central coordena e não impõe as regras propostas. Não é necessariamente um modelo a ser copiado e reproduzido, tampouco isento de conflitos e tensões frequentes, mas bom para pensar.

Os países da América do Sul têm seguido trilhas bem mais tortuosas, por sua tradição histórica, os processos de colonização, os violentos processos de ocupação de territórios e de desigualdades sociais de longa data. No Brasil, país com escala continental com uma população de 209,5 milhões de habitantes e com enormes diversidades sociais, culturais, étnicas, a gestão da pandemia nos leva a desafios imensos e ao encontro de paradoxos e ambivalências socioculturais já estruturais.

De um lado, o país apresenta forte atuação na pesquisa científica, incluindo a produção de conhecimento e de tratamento de doenças endêmicas, a exemplo da atuação da Fundação Oswaldo Cruz (Fiocruz), vinculada ao Ministério da Saúde, a mais destacada instituição de ciência e tecnologia em saúde da América Latina, e também das universidades públicas que se espalham por todo o país (ainda que diante de menos investimentos sistemáticos). De outro lado, há o país que é atravessado pela "política para si", que ameaça o espírito crítico e científico, a liberdade de pensamento e as responsabilidades. ${ }^{5}$

Racionalidades outras são presentes no sul do globo. Em texto recente publicado por Els Lagrou (2020), ao dar lugar aos Huni Kuin do Acre e do leste da floresta amazônica peruana, a antropóloga nos apresenta filosofias ameríndias, ontologias relacionais dessas minorias indígenas que habitam a América do Sul, como uma forma alternativa e mais global de compreender o universo 
da floresta habitado por uma multiplicidade de espécies que são sujeitos e negociam seu direito ao espaço e à própria vida. Outros estudos no âmbito das religiões afro-brasileiras, apontam para a sua imensa variedade e criatividade nas formas relacionais de compreensão do mundo, não havendo pois a existência de algo como uma doutrina unívoca. Nas grandes cidades brasileiras, líderes comunitários atuam de forma corajosa, coordenada e eficiente, distribuindo tarefas e papéis na organização de medidas de proteção e ajuda a moradores de seus bairros e favelas.

Os Kuikuro, no Alto Xingu, ${ }^{6}$ diante da gravidade da pandemia negada pelo governo e subestimada por muitas pessoas no Brasil, adotaram medidas de isolamento e restrições de contato localmente, fizeram campanhas visando arrecadar recursos para suprimentos médicos e usaram sua experiência com um surto de sarampo para enfrentar o coronavírus. Construíram uma casa de isolamento. Ao mesmo tempo, procuraram parcerias com pesquisadores de universidades, por exemplo, o Museu Paraense Emílio Goeldi, a Universidade Federal do Rio de Janeiro, a organização People's Palace Project no Reino Unido e também a Pennywise Foundation dos Estados Unidos.

As políticas, no seu sentido mais amplo, que em alguns âmbitos são ricas e complexas, em outros são esmagadas pela irresponsabilidade ou por completo descaso. Em meio à falta de ações e medidas coordenadas de governo, o Brasil na metade do mês de maio de 2020 registrava I3.I 49 mortes causadas pelo novo coronavírus, número que cresceu exponencialmente com perto de 200 mil casos confirmados da doença naquele momento. Diante da omissão deliberada do atual governo e de negação ou de distorção das evidências científicas, cuja tradição atravessa distintas esferas, a doença atingiu fortemente os centros urbanos, sendo especialmente crescente em periferias e favelas, mas também avançou tragicamente em meio a comunidades tradicionais e a populações indígenas. Em março de $202 \mathrm{I}$, o Brasil enfrentava o pior momento da pandemia até ali, com índices de contaminação elevados e número de pessoas que morreram em decorrência da doença do coronavírus que ultrapassa 300.000 .

Desde o início da pandemia em 2020, e ao longo de todo o ano que seguiu, o governo brasileiro negligenciou e mesmo impediu ações coordenadas pelo Ministério da Saúde que passou por quatro mudanças de ministro ao longo deste período. Os pronunciamentos oficiais e informais do presidente brasileiro quanto à gestão da crise sanitária no Brasil se destacaram nas manchetes dos jornais da imprensa brasileira e internacional pela negligência e pelo aumento descontrolado dos casos, pela omissão, pelo negacionismo expresso nos seus discursos, em que alegou sistematicamente não se tratar de uma pandemia, não haver necessidade de restrições como as medidas de isolamento ou distanciamento. Tratamentos e o uso de medicamentos comprovadamente ineficazes foram sistematicamente divulgados nos seus pronunciamentos e ações. 
Mais do que isso, conforme estudo publicado em janeiro de $202 \mathrm{I}, 7$ foram produzidos milhares de atos de obstrução das respostas locais, incluindo os relativos à retenção de recursos financeiros e à propaganda contra a saúde pública. Segundo dados levantados pelo estudo, o governo federal sistematicamente incitou a população à exposição do vírus, desacreditou as autoridades sanitárias, disseminou informações falsas sobre saúde, como a existência de tratamento precoce não comprovado para a covid-I9, e estimulou a desobediência às recomendações de saúde pública elementares para a contenção do vírus, como usar máscaras, evitar aglomerações e respeitar as medidas de quarentena.

As alternativas sociais mais capilares, relacionais, talvez sejam as que devem ser mais cuidadas e as que potencializam ações mais dinâmicas, participativas e adequadas a cada realidade. Como refletia Weber, a ciência contribui para o "ganho da clareza" sobre si e sobre os processos sociais. Que a clareza possa ser conquistada em cada uma das partes deste imenso planeta. E as experiências sociais possam abrigar horizontes alternativos.

Recebido em 06/I I/2020 | Revisto em 06/04/202 I | Aprovado em 2I/05/202 I

Renata de Sá Gonçalves é professora do Departamento de Antropologia e do Programa de Pós-graduação em Antropologia da Universidade Federal Fluminense. Foi professora visitante no Interdisciplinary Centre for Global South Studies da Universität Tübingen, na Alemanha (2020-202I). É coordenadora do Núcleo de Antropologia das Artes, Rituais e Sociabilidades Urbanas (Narua/UFF). É atualmente coordenadora do Comitê de Patrimônio e Museus da

Associação Brasileira de Antropologia (202 I-2022). Publicou recentemente "Walking through Rio de Janeiro's Little Africa: places and contested borders" e, em coautoria, A antropologia na esfera pública: patrimônios culturais e museus e Carnaval sem fronteiras. As escolas de samba e suas artes mundo afora. 


\section{NOTAS}

I Agradeço aos pareceristas anônimos as sugestivas contribuições para a versão atual do artigo e à equipe do Interdisciplinary Centre for Global South Studies da Universidade de Tübingen, na Alemanha, o acolhimento ao longo de pós-doutorado em 2019 e 2020.

2 Vídeo do discurso disponível em: https://youtu.be/caUFMAipVYI. Acesso em 9 jun. 2020.

3 Notícia da Universidade de Tübingen sobre a indicação do melhor discurso de ano. Disponível em: https://unituebingen.de/universitaet/aktuelles-und-publikationen/ newsfullview-aktuell/article/es-ist-ernst-nehmen-sie-esauch-ernst/. Acesso em I8 dez. 2020.

4 Segundo Villas Bôas (2008), questiona-se se Max Weber pronunciou as conferências "Ciência como vocação" e "Política como vocação" em IgI8 ou consecutivamente em I9I7 e I9I8. Estudiosos de Weber concordam que as duas conferências foram dirigidas aos jovens estudantes alemães da Associação dos Estudantes Livres da Baviera, que convidou o mestre e promoveu os dois eventos na Universidade de Munique. Fatos históricos relevantes haviam modificado o destino político e geopolítico da Europa naqueles anos. O Segundo Império alemão sofrera uma grave derrota militar, enquanto a Revolução de Outubro fora vitoriosa na Rússia; desfizeram-se as monarquias e os impérios austro-húngaro, germano e turco-otomano.

5 Interessa lembrar, como formulado pela socióloga Villas Bôas (20I4: I7), que a recepção de algumas proposições de Weber na sociologia brasileira é caracterizada ora pelo silêncio, ora pelo desinteresse - "Uma parte notável da intelectualidade brasileira almejava transformar o país em uma sociedade moderna. [...] Se apostaram em valores, esses foram os valores da liberdade de fazer uso da ciência para agir de acordo com seus resultados, certamente uma tarefa cuja realização exigia seguir direção contrária ao ascetismo e à autolimitação".

6 Segundo os dados publicados na reportagem, "mais de 45 mil casos de covid-I9 e 622 mortes foram registrados entre indígenas no Brasil, de acordo com dados oficiais da Secretaria de Saúde Indígena (Sesai). A Articulação dos Povos Indígenas do Brasil (Apib), entretanto, afirma que os números são bem mais altos e contabilizou I.022 mor- 
tes e pelo menos 5 I mil casos até terça (23/03/202I). Publicado pela BBC News em https://noticias.uol.com.br/ ultimas-noticias/bbc/202I/03/28/indigenas-kuikoro-venceram-pandemia-com-base-na-ciencia-e-financiamentocoletivo.htm. Acesso em 28 mar. 202I.

7 As 3.049 normas relativas à covid-I9 coletadas pelo referido levantamento no âmbito da União constituem um acervo normativo que resulta do embate entre a estratégia de propagação do vírus conduzida de forma sistemática pelo governo federal e as tentativas de resistência dos demais poderes, dos entes federativos, de instituições independentes e da sociedade (Cepedisa \& Conectas, 202I).

\section{REFERÊNCIAS}

Cepedisa (Centro de Pesquisa de Direito Sanitário) \& ONG Conectas Direitos Humanos. (202I). Mapeamento e análise das normas jurídicas de resposta à Covid-I9 no Brasil. Boletim Direitos na Pandemia, Io.

Lagrou, Els. (2020). Nisun: a vingança do povo morcego e o que ele pode nos ensinar sobre o novo coronavírus. Disponível em https://blogbvps.wordpress.com/2020/04/13/nisuna-vinganca-do-povo-morcego-e-o-que-ele-pode-nos-ensinar-sobre-o-novo-corona-virus-por-els-lagrou/. Acesso em 20 jun. 2020.

Speck, Bruno Wilhelm. (2020). A pandemia e a extrema-direita na Alemanha. In: Grossi, Miriam Pillar \& Toniol, Rodrigo (orgs.). Cientistas sociais e o coronavírus [recurso eletrônico]. São Paulo/ Florianópolis: Anpocs/Tribo da Ilha.

Villas Bôas, Glaucia. (20I4). A recepção controversa de Max Weber no Brasil (I940-I980). Dados, 57/I, p. 5-33.

Villas Bôas, Glaucia. (2008). Weber entre duas vocações. Cult, Revista Brasileira de Cultura, I I/I24, p. 58-6I. Disponível em: https://revistacult.uol.com.br/home/max-weber-entreduas-vocacoes/. Acesso em 20 jun. 2020.

Weber, Max. (I972a). A ciência como vocação. In: Ciência e política: duas vocações. Trad. Leonidas Hegenber e Octany Silveira da Mota. São Paulo: Cultrix.

Weber, Max. (1972b). A política como vocação. In: Ciência e política: duas vocações. Trad. Leonidas Hegenber e Octany Silveira da Mota. São Paulo: Cultrix. 
Palavras-chave

Ciência, política;

Alemanha; covid-I9.

Keywords

Science; politics;

Germany; covid-I 9.

\section{A CIÊNCIA E A POLÍTICA COMO VOCAÇÃO} -O DISCURSO DE MERKEL E A PRIMEIRA ONDA DA PANDEMIA DE COVID-19 NA ALEMANHA

\section{Resumo}

O texto se propõe a analisar a gestão da crise da covid-I9 no ano de 2020 estabelecendo alguns pontos de destaque da condução pública da chanceler Angela Merkel na Alemanha, em diálogo com as conferências clássicas de Max Weber "A ciência como vocação" e "A política como vocação" de I9I9. Por fim, possibilita alguns aspectos de contraste com a condução da pandemia nos países do Sul no Global, especialmente no Brasil, tanto na sua produção coletiva e criativa, quanto na sua forma de negligência à ciência e à política presentes na condução do atual presidente.

\section{SCIENCE AND POLITICS AS A VOCATION -MERKEL'S SPEECH AND THE FIRST WAVE OF THE COVID-19 PANDEMIC IN GERMANY}

\section{Abstract}

The text proposes to analyze the management of the covid-I 9 crisis in the year 2020 by establishing some highlights of the public conduct of Chancellor Angela Merkel in Germany, and in dialogue with Max Weber's classic conferences "Science as a vocation" and "Politics as a vocation" of I9I9. Finally, it allows for some contrasting aspects with the pandemic's conduct in the Global South, especially in Brazil, both in its collective and creative production, and in its neglect of science and politics, in the conduct of the current president. 